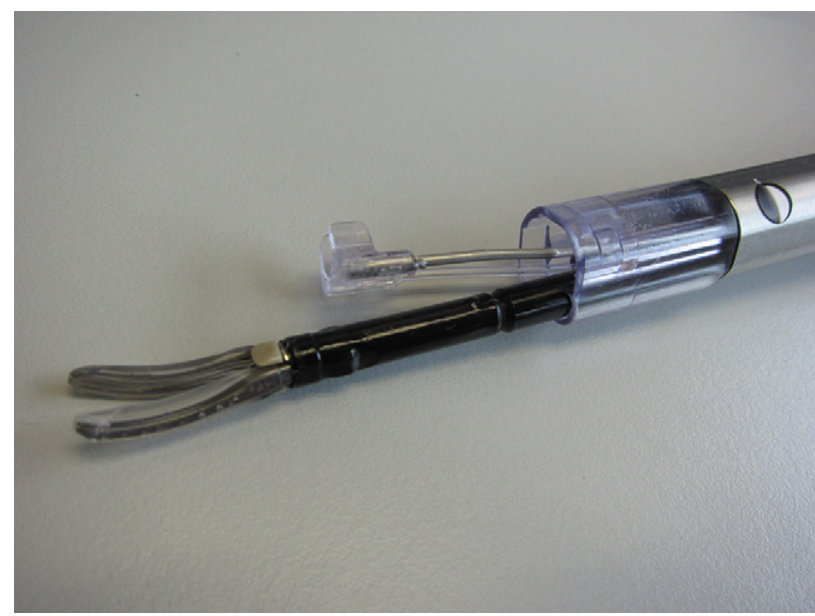

FIGURE 1. Instrumentation at the end of the Hemopro 2 Vasoview device (MAQUET Medical Systems, Wayne, NJ).

injury and associated complications, including Horner's syndrome. In addition, the combined features of the Vasoview device allow a single surgeon to perform the sympathectomy, being both the thoracoscopic camera holder and the operator. Our preferred supine patient position makes redraping or repositioning during the bilateral procedure unnecessary, saving time and reducing wound contamination risks. A potential disadvantage of the single-port approach is the limited ability to deal with pleural adhesions and bleeding from chest wall vessels.

\section{CONCLUSIONS}

Single-port VATS sympathectomy for palmar hyperhidrosis with the Vasoview Hemopro 2 device can be performed safely, with minimal chest wall access trauma and satisfactory cosmesis results, without compromising the early surgical outcomes. The long-term outcomes and

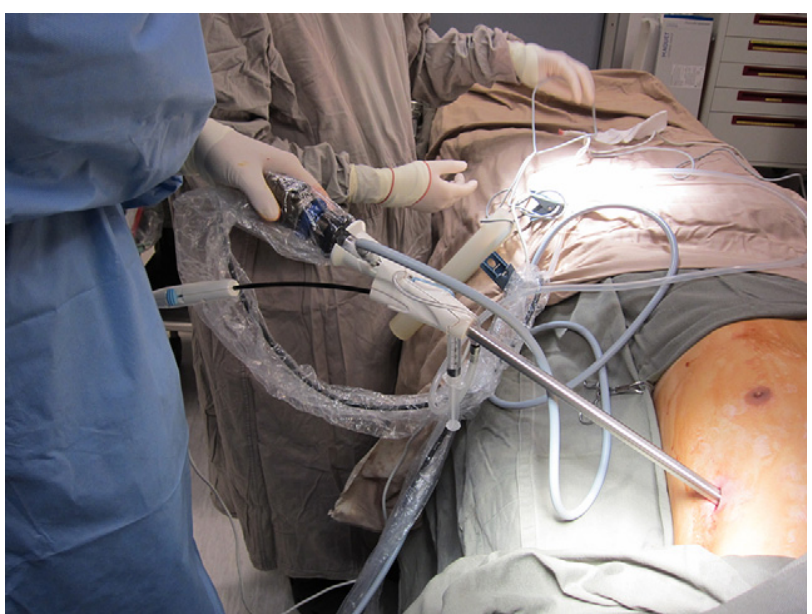

FIGURE 2. Operating room photograph illustrating the position, Vasoview device, and surgical access for sympathectomy.

potential benefits of this single-port technique warrant further investigation.

\section{References}

1. Yim AP, Liu HP, Lee TW, Wan S, Arifi AA. 'Needlescopic' video-assisted thoracic surgery for palmar hyperhidrosis. Eur J Cardiothorac Surg. 2000;17: 697-701.

2. Miller DL, Bryant AS, Force SD, Miller JI Jr. Effect of sympathectomy level on the incidence of compensatory hyperhidrosis after sympathectomy for palmar hyperhidrosis. J Thorac Cardiovasc Surg. 2009;138:581-5.

3. Zenati MA, Shroyer AL, Collins JF, Hattler B, Ota T, Almassi GH, et al. Impact of endoscopic versus open saphenous vein harvest technique on late coronary artery bypass grafting patient outcomes in the ROOBY (Randomized On/Off Bypass) Trial. J Thorac Cardiovasc Surg. 2011;141:338-44.

4. Bouma W, Klinkenberg TJ, Mariani MA. Bilateral single-port thoracoscopic sympathectomy with the VasoView device in the treatment of palmar and axillary hyperhidrosis. Interact Cardiovasc Thorac Surg. 2011;12:106-9.

5. Rojas-Pena A, Koch KL, Heitner HD, Hall CM, Bergin IL, Cook KE. Quantification of thermal spread and burst pressure after endoscopic vessel harvesting: a comparison of 2 commercially available devices. $J$ Thorac Cardiovasc Surg. 2011;142:203-8.

\title{
Posterior pulmonary artery bifurcation side-to-side arterioplasty for branch pulmonary artery stenosis
}

\author{
Jenelle A. Holst, BA, ${ }^{a}$ David N. Campbell, MD, ${ }^{\text {a,b }}$ James Jaggers, MD,,${ }^{a, b}$ and Max B. Mitchell, MD, ${ }^{\text {a,b }}$ \\ Aurora, Colo
}

\footnotetext{
From the University of Colorado Denver School of Medicine, ${ }^{\text {a }}$ Aurora, Colo; and Children's Hospital Heart Institute, ${ }^{\mathrm{b}}$ Aurora, Colo.

Disclosures: Authors have nothing to disclose with regard to commercial support.

Received for publication Jan 25, 2012; revisions received May 13, 2012; accepted for publication June 12, 2012; available ahead of print July 2, 2012.

Address for reprints: Max B. Mitchell, MD, Children's Hospital Colorado Heart Institute, 13123 East 16th Ave, B-200, Aurora, CO 80045 (E-mail: max.mitchell@ childrenscolorado.org).

J Thorac Cardiovasc Surg 2012;144:1257-9

$0022-5223 / \$ 36.00$

Copyright (c) 2012 by The American Association for Thoracic Surgery

http://dx.doi.org/10.1016/j.jtcvs.2012.06.021
}

Right ventricular outflow tract (RVOT) reconstructions involving a right ventricle to pulmonary artery (RV-PA) conduit or transannular patch almost universally obligate subsequent pulmonary valve replacement. ${ }^{1}$ In some patients, ostial branch pulmonary artery stenosis (BPAS) requires repair concomitantly with pulmonary valve replacement. ${ }^{2}$ Growth after repair early in life displaces the pulmonary artery bifurcation anteriorly, resulting in an abnormally parallel course of the proximal branch 

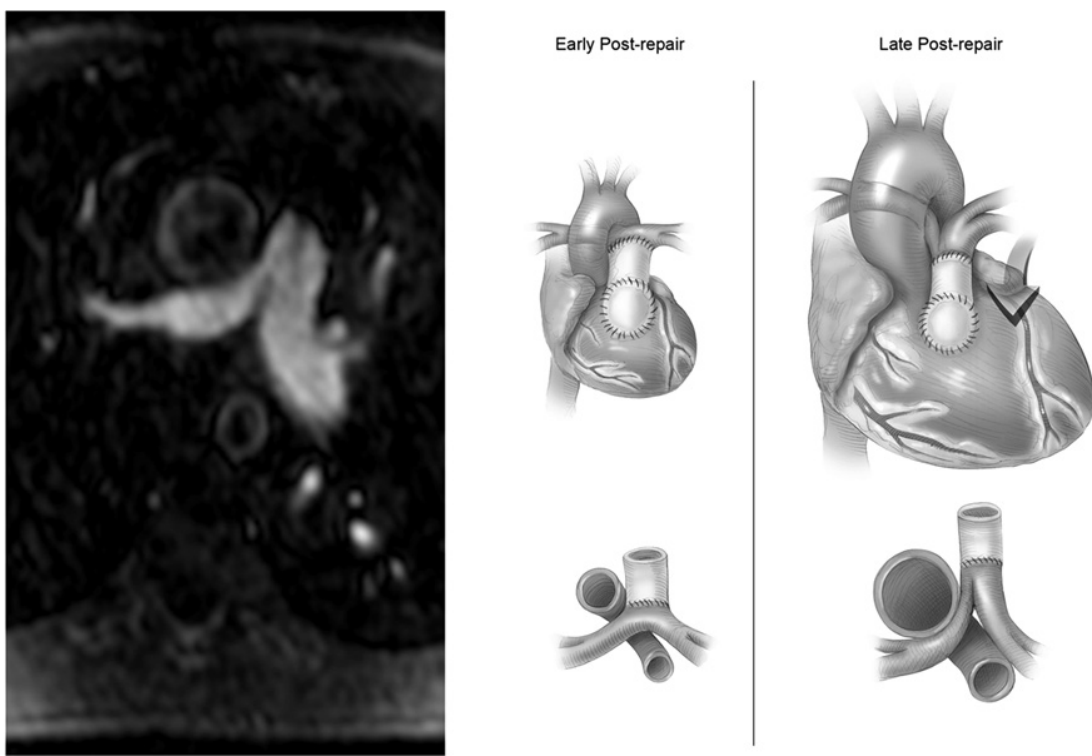

FIGURE 1. Left, Anterior displacement of pulmonary artery bifurcation and ostial stenosis of right pulmonary artery by magnetic resonance angiogram 8 years after neonatal repair of truncus areteriosus. Middle, Orientation of pulmonary artery bifurcation early after repair. Right, Growth-induced distortion of pulmonary artery bifurcation and right pulmonary artery ostial stenosis late after repair.

pulmonary arteries and a prominent posterior ridge at the bifurcation resembling the carina tracheae as viewed at bronchoscopy (Figure 1). Posterior pulmonary artery bifurcation side-to-side arterioplasty is a simple method to correct ostial BPAS in this setting.

\section{CLINICAL SUMMARY}

After repeat sternotomy and initiation of cardiopulmonary bypass, calcified conduit or transannular patch material is removed as required to accommodate a new conduit or bioprosthesis. The branches are assessed by working within the main pulmonary artery (Figure 2, A). If there is a relatively parallel course through the distal extent of BPAS, the carina is incised posteriorly through the back wall of each pulmonary artery branch with a single incision (Figure 2, $B$ and $C$ ). Fine monofilament suture is used to reconstruct the bifurcation, orienting the suture line perpendicular to the incision as with Heineke-Mikulicz pyloroplasty (Figure 2,D). When a repeat conduit is intended, the main pulmonary artery diameter is often small, and an anterior incision onto 1 or both branches is necessary. Extension onto the side away from the aorta (usually left) is easiest, and posterior bifurcationplasty facilitates the creation of an adequate lumen to the stenotic side.

\section{DISCUSSION}

During redo RVOT reconstruction, dissection of the pulmonary arteries to address BPAS can be complicated by dense adhesions and the proximity of the left phrenic nerve. Posterior pulmonary artery bifurcation side-to-side arterioplasty can limit the required dissection and is particularly helpful when the aorta and adjacent conduit are densely adherent. We have used this technique with redo RVOT reconstructions in 22 patients. All patients underwent primary RVOT reconstruction as neonates or during early infancy and had significant time (mean, $6.4 \pm 3.0$ years) to reoperation. Eight patients had right-sided BPAS, and all patients had prior repair of a conotruncal anomaly associated with an inherently or surgically enlarged proximal ascending aorta (truncus arteriosus, $\mathrm{n}=4$; Ross/Ross Kono, $\mathrm{n}=4$ ) and placement of an RVPA conduit. With growth, anterior and inferior traction on the bifurcation caused by the fixed position of the proximal conduit suture line lead to bow-stringing of the right pulmonary artery against the enlarged ascending aorta (Figure 1). This displacement of the bifurcation leads to a near parallel course of the proximal branch pulmonary arteries. We hypothesize that anterior displacement of the pulmonary artery carina with compression of the origin of the pulmonary artery branch against the aorta medially leads to ostial stenosis on the side adjacent to ascending aorta. Six patients had left-sided BPAS. One patient had undergone prior Rastelli repair for d-transposition/pulmonary stenosis/ventricular septal defect with the RV-PA conduit placed to the right of the ascending aorta, and the mechanism described was likely. The remaining 5 patients with left-sided BPAS occurred in patients who underwent repair of tetralogy of Fallot (TOF) with transannular patch extension onto the left pulmonary artery in early infancy. Presumably, patient growth with a fixed patch length may tether the origin of the left pulmonary artery anteriorly, resulting in 


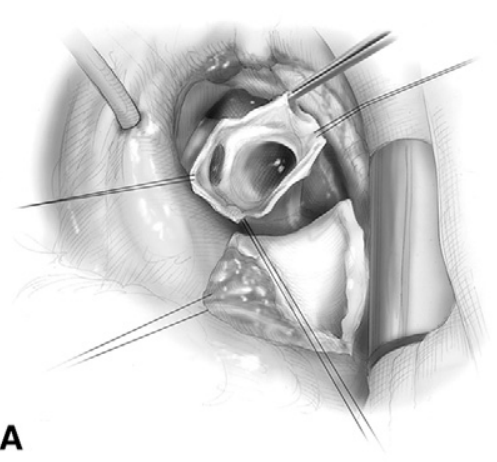

A

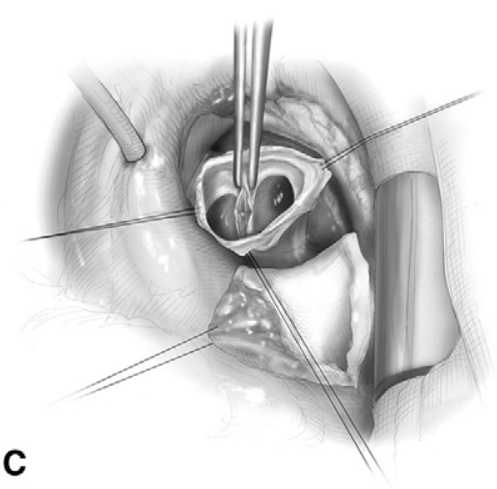

B
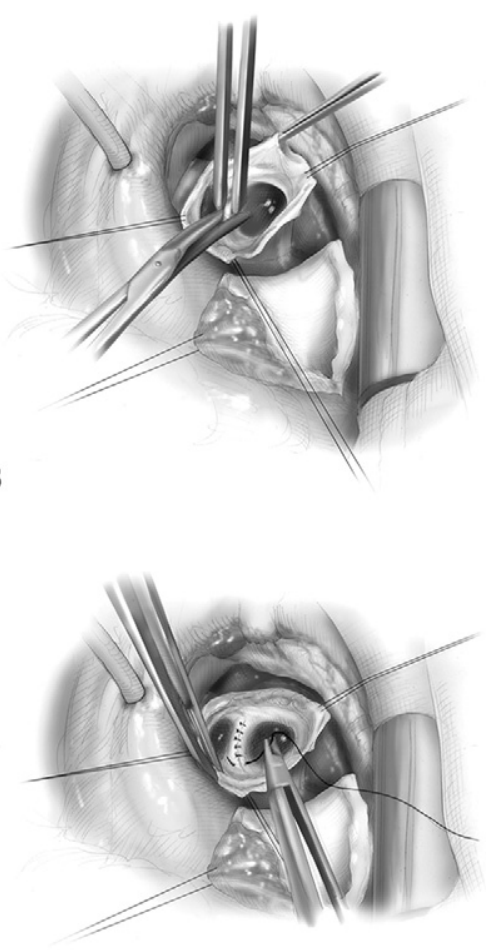

D

FIGURE 2. A, Internal view of pulmonary artery bifurcation with right pulmonary artery ostial stenosis. B, Posterior incision through the ridge separating branch orifices. C, View after incision. D, Incision closed transversely.

a more parallel course of the proximal branches, and may contribute to recurrent or new left-sided ostial stenosis.

We have also used this technique in 3 patients with bilateral BPAS and 5 patients without BPAS. Patients with bilateral BPAS (2 with truncus arteriosus, 1 with TOF/ pulmonary atresia) underwent the technique combined with anterior incisions onto each branch to augment the ostial diameter on each side. In patients without BPAS, this technique was used to relocate the bifurcation posteriorly to increase the distance from the right ventriculotomy to fit a new longer RV-PA conduit (4 with truncus arteriosus, 1 with TOF/pulmonary atresia). This has been particularly helpful during implantation of Contegra (Medtronic Inc, Minneapolis, Minn) conduits because of the significantly longer leaflet heights of the bovine jugular valve compared with allograft valves of the same diameter. ${ }^{3}$

\section{CONCLUSIONS}

We are unaware of other descriptions of posterior pulmonary artery bifurcation side-to-side arterioplasty as applied in the reoperative setting. $\mathrm{Mee}^{4}$ previously described a similar technique used with primary repair of TOF. We have also used this technique at primary TOF repair; however, we have found this technique infrequently applicable in this setting because the proximal branch pulmonary arteries only rarely diverge at an adequately acute angle to permit this technique.

\section{References}

1. Niemantsverdriet MB, Ottenkamp J, Gauvreau K, Del Nido PJ, Hazenkamp MG, Jenkins KJ. Determinants of right ventricular outflow tract conduit longevity: a multinational analysis. Congenit Heart Dis. 2008;3: 176-84.

2. Discigil B, Dearani JA, Puga FJ, Schaff HV, Hagler DJ, Warnes CA, et al. Late pulmonary valve replacement after repair of tetralogy of Fallot. $J$ Thorac Cardiovasc Surg. 2001;121:344-51.

3. Boethig D, Ernst F, Sarikouch S, Norozi K, Lotz J, Opherk P, et al. Physical stress testing of bovine jugular veins using magnetic resonance imaging, echocardiography and electrical velocimetry. Int Cardiovasc Thorac Surg. 2010;10: 877-83.

4. Mee RBB. Transatrial transpulmonary repair of tetralogy of Fallot. In: Yacoub M, ed. Annual of Cardiac Surgery. 8th ed. Philadelphia: Lippincott Williams \& Wilkins; 1995:141-7. 